\title{
The Teaching of Psychology in Colombia: The Challenges for the Discipline and High Quality
}

\author{
La enseñanza de la Psicología en Colombia: los retos para la disciplina y la alta calidad
}

William Cornejo Ochoa'

1. Full member of the Colombian Association of Neurology (ACN) and Child Neurology Colombian Association (Asconi)-Group Director of Research in Child and Adolescent Disorders (PEDIACIENCIAS)-Titular Professor Department of Pediatrics, School of Medicine, Universidad de Antioquia, Medellín, Colombia. * Corresponding author. jose.cornejo@udea.edu.co

According to the statistics published by the Colombian National Information System of Higher Education (2017), there are 175 education programs in Psychology in Colombia, of which 125 are currently active. Out of these, only 38 (30.4\%) were given high-quality accreditation while the other 87 (69.6\%) just meet the minimum quality conditions, according to the requirements set by the Ministry of National Education for quality registration. This accreditation is an acknowledgement of the superior standards the institutions and academic programs adhere to, and is thereby acknowledged as such by the Colombian state through the National Accreditation Council (CNA), that is governed by the agreements issued for that purpose by the National Council of Higher Education (CESU) the institution in charge of planning, coordinating, and advising the Ministry of National Education on higher educational matters.

In 2016, Colombian National Information System of Higher Education registered a total of 875 psychology graduates from public institutions and 5,363 from private universities nationwide. The growth in the number of programs, student enrollments, and graduates, especially in the last two decades, raises some relevant questions: How have the curricular contents and academic activities evolved and been updated? What are the fields of practice currently available? How has research progressed and what are its implications for university education? How is the student-teacher relationship like and what is the level of postgraduate, educational, and linguistic (second language) qualification of the teachers? What type of contract do teachers have? What has been the development in terms of infrastructure and physical plant?

These are just some of the questions that need to be answered in order to fully appreciate or estimate increase in quality standards. A prosperous and rapidly developing educational system cannot afford the prodigality of having stagnant academic programs. Undoubtedly, in response to modernization, scientific and technological advancements, cultural transformations, and the reconstruction of the social fabric shifting to the post-conflict era, higher educational institutions in Colombia would need to have effective processes to adapt and continue the improvements of the new educational requirements set for psychology professionals. However, the increase in the number of psychology students in a country with a high demand for professionals in this field due to its current social and health situation-but one that does not show coherence between the educational and labor markets-is a concern that universities, within the framework of their autonomy, need to address in order to strengthen self-regulation.

In line with the curricular and professional training processes psychologists undergo in Colombia, Blanco and Botella (1995) reflected, more than 20 years ago, on the suspicious and excessive overcrowding of psychology programs in Spain, along with the light demands of the curricula that leads to the formation of professionals with no critical thinking of reality, poor technical skills, and a theoretical laxity bordering on mediocrity. In consequence, it is deemed a responsibility of the educational institutions to ensure improvement and constant updating of the curricula of the programs they offer. Neglecting this task would affect the comprehensive and qualified training of future professionals in various fields of psychological knowledge, limiting their technical, clinical, and critical skills needed to compete in an environment that favors innovation, clinical skills, and knowledge of cognitive and social neurosciences. In this new 
context, professionals would need to participate in the prevention, diagnosis, rehabilitation, and treatment of conditions or disorders related to physical, mental, or cerebral issues, as well as in organizational dynamics, psychotherapeutic interventions, administration and interpretation of psychological tests, among other processes, and adjust to the contextual policies that underlie a particular social reality.

It is also worth noting that $53 \%$ of the psychology programs listed by the Colombian Association of Psychology Faculties (ASCOFAPSI, 2017) are currently active. ASCOFAPSI is an academic entity that promotes, from the discipline, the improvement of the training processes of psychologists in Colombia. Unfortunately, the limited participation of faculties or programs makes it difficult to access the guidance and support provided by ASCOFAPSI as part of its missionary functions consisting of promoting the quality of training for psychologists. Moreover, it restricts participation in the network of researchers, alliances between research groups, continuous education, and qualification of formative, cooperative, and interinstitutional processes.

In this scenario that was outlined to focus on the training of psychologists in Colombia, there is a lingering issue that calls for prompt review and resolution: the inclusion of psychology programs in health sciences. Currently, according to SNIES, the only undergraduate program recognized in health sciences is that offered by Universidad Santo Tomas, in the Colombian department of Meta. Most of the psychology programs are classified by the Ministry of National Education as part of social sciences.

In this regard, the educational formation of contemporary psychologists has a big challenge to face in the health sciences. With the progress made in human genome research, numerous studies have identified different epigenetic mechanisms and the effects of environmental and psychological factors on the development of a disease. This suggests that behavior and stressful events may reshape, in the long term, the genomic function and, therefore, the clinical evolution of many diseases (Cadet, 2016; Cecil et al., 2016; Champagne, 2010; Choleris, Galea, Sohrabji, \& Frick, 2018; González-Pardo \& Pérez Álvarez, 2013; Yehuda \& Bierer, 2009).

Universities too face a great challenge in terms of the curricular guidelines they set for their psychology programs. Their advancements should include the promotion of a more modern method of teaching, framed by the epidemiological characteristics of the country, the needs of the environment, and the qualification of the professional profiles that allow current psychologists to be part, within the field of health, of interdisciplinary work teams that consider psychology as a discipline that is in constant interaction with other fields of knowledge, in order to achieve therapeutic efficacy and a better prognosis in the treatment of diseases and disorders.

In Colombia, as in other Latin American countries, a quality assurance system is being developed and strengthened so as to establish a better control and supervision of higher educational institutions and their undergraduate and postgraduate programs.

The process of construction, as well as the organizational and normative strengthening of this system for higher education should continue and, with the same spirit, delve deeper into the discussion on the obligatory nature of the accreditation of the programs that involve public health care.

Consequently, the Ministry of National Education, as the institution responsible for promoting quality in the disciplinary and contemporary teaching of psychology as a profession in Colombia, should consider:

a. (In line with the advancements made by COLPSIC and ASCOFAPSI in relation to the disciplinary and professional fields.) Determining the curricular requirements needed in the training of psychologists, essential for the profession to be included in health sciences. This condition will contribute to the inclusion of new fields of professional practice.

b. Reviewing the curricular proposal of the programs, according to the national situation and in response to the scientific advances, both achieved and in progress, for the study of human behavior.

c. Evaluating the congruence of the academictraining and the disciplinary quality of the profession, in tune with the advancements obtained from the discipline in the Latin American context, in order to facilitate exchange, homologation, and academic alliances in the region.

d. Promoting and supporting, from the high quality standpoint, the academic and differentiating factor of the profession from each of the institutions.

e. Establishing a close and continuous communication with COLPSIC and ASCOFAPSI, in order to implement common guidelines for the qualification of professional teaching processes and to promote high-quality standards in exercising psychology.

f. Supervising the academic quality of the programs and establishing planning policies for the training of human resources. This analysis also requires the participation of students' and graduates' associations that can contribute to reformulating processes that favor quality in the discipline and, from them, exercise social and academic control over the educational and pedagogical quality of the institutions.

Finally, regarding research on psychology in Colombia, Colciencias (2016) has classified 170 research groups: 24 in category A1, 28 in category A, 36 in category B, and the rest in category C. This 
situation deserves a more detailed analysis that includes the level and quality of intellectual production within the discipline, the contributions to society and the development of the country, and the distribution according to higher educational institutions. This research scenario will improve in the national context with the advancements made in the academic quality of the institutions. Only from that point we will be able to configure a discipline for the scientific and cultural development in the 21st century.

\section{References}

ASCOFAPSI. (2017). Búsqueda de programas de pregrado de Psicología [Data file]. Recovered from: http://observatorio.ascofapsi.org.co/ programas-de-pregrado/

Blanco, A., \& Botella, J. (1995). La enseñanza de la Psicología en España a la luz de los nuevos planes de estudio. Papeles del Psicólogo, 62, 29-47.

Cadet, J. L. (2016). Epigenetics of stress, addiction, and resilience: Therapeutic Implications. Molecular Neurobiology, 53(1), 545-560. doi: 10.1007/ s12035-014-9040-y

Cecil, C. A., Smith, R. G., Walton, E., Mill, J., McCrory, E. J., \& Viding, E. (2016). Epigenetic signatures of childhood abuse and neglect: Implications for psychiatric vulnerability. Journal of Psychiatric Research, 83, 184-194. doi: 10.1016/j. jpsychires.2016.09.010

Champagne, F. A. (2010). Early adversity and developmental outcomes: Interaction between genetics, epigenetics, and social experiences across the life span. Perspectives on Psychological Science, 5(5), 564-574. doi: $10.1177 / 1745691610383494$

Choleris, E., Galea, L. A. M., Sohrabji, F., \& Frick, K. M. (2018). Sex differences in the brain: Implications for behavioral and biomedical research. Neuroscience \& Biobehavioral Reviews, 85, 126145. doi: 10.1016/j.neubiorev.2017.07.005

Colciencias. (2016). Resultados de convocatorias de reconocimineto y medición de grupos de investigación (Report). Recovered from: http://www.colciencias.gov.co/resultadosconvocatorias-reconocimineto-y-mediciongrupos-investigacion

Colombian National Information System of Higher Education. (2016). Módulo de consultas: Búsqueda de programas de instituciones de educación superior [Data file]. Recovered from: https://snies.mineducacion.gov.co/ consultasnies/programa\#
Colombian National Information System of Higher Education. (2017). Módulo de consultas: Busqueda de instituciones de educación superior aprobadas [Data file]. Recovered from: https:// snies.mineducacion.gov.co/consultasnies/ institucion\#

González-Pardo, H., \& Pérez Álvarez, M. (2013). Epigenetics and its implications for Psychology. Psicothema, 25(1), 3-12. doi: 10.7334/ psicothema2012.327

Yehuda, R., \& Bierer, L. M. (2009). The relevance of epigenetics to PTSD: implications for the DSM-V. Journal of Traumatic Stress, 22(5), 427-434. doi: $10.1002 /$ jts. 20448 